\title{
IncRNA028466 regulates Th1/Th2 cytokine expression and associates with Echinococcus granulosus antigen P29 immunity
}

Chan Wang ${ }^{1,3+}$, Song-Hao Yang ${ }^{1,3+}{ }^{+}$Nan Niu $^{1,3}$, Jia Tao ${ }^{1,3}$, Xian-Cai Du ${ }^{1,3}$, Ji-Hui Yang ${ }^{2,3}$, Ming-Xing Zhu $u^{1,2,3}$, Ya-Na Wang ${ }^{1,3}$ and Wei Zhao $2,3^{*}$ (1)

\begin{abstract}
Background: Cystic echinococcosis (CE) is a parasitic disease that is caused by Echinococcus granulosus (Eg). The recombinant Echinococcus granulosus antigen P29 (rEg.P29) was shown to confer effective immunity to sheep and mice during E. granulosus secondary infection in our previous study. In this study, we sought to investigate the ability of long noncoding RNA 028466 (IncRNA028466) as a regulator for the protective immunity mediated by rEg.P29 vaccination and to study the effects of IncRNA028466 on $\mathrm{CD}^{+} \mathrm{T}$ cell differentiation in mice spleen.
\end{abstract}

Methods: Female BALB/c mice were divided into two groups and were vaccinated subcutaneously with rEg.P29 antigen and PBS as a control (12 mice each group). Following prime-boost vaccination, $C D 4^{+} \mathrm{T}, \mathrm{CD} 8^{+} \mathrm{T}$, and $\mathrm{B}$ cells from the spleen were isolated by flow cytometry. Quantitative real-time PCR (qRT-PCR) was performed to measure the expression of IncRNA028466 in these three kinds of cells. Then, IncRNA028466 was overexpressed and knocked down in naive $C D 4^{+} T$ cells, and Th1 and Th2 cytokine expression was detected. qRT-PCR, western blot, and ELISA were performed to evaluate the production of IFN- $\gamma$, IL-2, IL-4, and IL-10, and flow cytometry was performed to detect the differentiation of Th1 and Th2 subgroups.

Results: IncRNA028466 was significantly decreased after the second week of immunization with rEg.P29 antigen. The proportion of $\mathrm{CD}^{+}{ }^{+} \mathrm{T}$ cells was increased after rEg.P29 immunization. Overexpression of IncRNA028466 facilitated the production of IL-4, IL-10 and suppressed the production of IFN- $\gamma$, IL-2. Furthermore, after transfection with siRNA028466, IL-2 production was facilitated and IL-10 production was suppressed in naive CD4 ${ }^{+} \mathrm{T}$ cells.

Conclusions: Immunization with rEg.P29 downregulated the expression of IncRNA028466, which was related to a higher Th1 immune response and a lower Th2 immune response. Our results suggest that IncRNA028466 may be involved in rEg.P29-mediated immune response by regulating cytokine expression of Th1 and Th2.

Keywords: Echinococcus granulosus, Long noncoding RNA 028466, Echinococcus granulosus antigen P29, CD4+ ${ }^{+}$cell, Cytokines

*Correspondence: Weizhao@nxmu.edu.cn

${ }^{\dagger}$ Chan Wang and Song-Hao Yang contributed equally to this work ${ }^{3}$ Ningxia Key Laboratory of Prevention and Control of Common Infectious Diseases of Ningxia Medical University, Yinchuan 750004, Ningxia Hui Autonomous Region, People's Republic of China

Full list of author information is available at the end of the article

\section{Background}

Cystic echinococcosis (CE), also known as hydatid disease, is a worldwide chronic parasitic disease, threatening the health of livestock and humans [1]. Humans are exposed to the eggs of Echinococcus granulosus after close contact with infected livestock or contaminated food [2, 3]. At present, diagnosis of human echinococcosis relies

c) The Author(s) 2021. This article is licensed under a Creative Commons Attribution 4.0 International License, which permits use, sharing, adaptation, distribution and reproduction in any medium or format, as long as you give appropriate credit to the original author(s) and the source, provide a link to the Creative Commons licence, and indicate if changes were made. The images or other third party material in this article are included in the article's Creative Commons licence, unless indicated otherwise in a credit line to the material. If material is not included in the article's Creative Commons licence and your intended use is not permitted by statutory regulation or exceeds the permitted use, you will need to obtain permission directly from the copyright holder. To view a copy of this licence, visit http://creativeco mmons.org/licenses/by/4.0/. The Creative Commons Public Domain Dedication waiver (http://creativecommons.org/publicdomain/ zero/1.0/) applies to the data made available in this article, unless otherwise stated in a credit line to the data. 
mainly on imaging techniques. The life of the pathogen in the human body is relatively long, ranging from 1 to 30 years, and the symptoms of the initial infection are not obvious. Therefore, it is difficult to diagnose, treat, and control $[2,4,5]$. Due to the limitations of current diagnostic and therapeutic measures, numerous studies have been carried out in the field of immunology associated with E. granulosus infection in the hope of developing vaccines [6, 7]. Vaccination would be an effective preventive healthcare measure against echinococcosis $[1$, 8]. Due to the complicated host-parasite relationship [9], there is still no commercial vaccine.

Thus far, there have been some effective antigens as vaccine candidates for the prevention of CE. Vaccination of intermediate hosts of E. granulosus with the $E g 95$ antigen has induced remarkable protective efficacy [4, 10]. Another study [11] documented the P29 protein as a 29-kDa antigen, which was characterized by E. granulosus protoscolex-derived soluble antigen [12, 13]. Our previous studies confirmed that vaccination of $\mathrm{rEg} g 29$ in sheep and mice carrying infection of E. granulosus eggs resulted in remarkable protective efficacy and induced Th1 cell to produce IFN- $\gamma$ against E. granulosus infection $[13,14]$. However, the mechanism of how the $r E g \mathrm{P} 29$ antigen influenced the host immune responses and regulated the differentiation of $\mathrm{CD} 4^{+} \mathrm{T}$ cells is still unclear.

Understanding the immune response between host and parasite is essential [15]. The role of $\mathrm{CD} 4^{+} \mathrm{T}$ cells in bacterial, viral, and parasitic infections and the adaptive immune system is important [16-18]. The distinguishing feature of the immune response caused by E. granulosus is that Th1- and Th2-type immune responses coexist [19]. It is commonly accepted that in most parasitic diseases, Th1 or Th2-type response is able to control pathogens; early Th1 cell activation confers host protective immunity, while Th 2 cell activation is related to the progression of the chronic stage when infected with E. granulosus $[20,21]$. The switch from a Th2 to a Th1 type of response seems to be required for a protective phenotype [22]. A polarized cytokine response plays an important role in some parasitic diseases where Th1- or Th2-type reactions are associated with susceptibility or resistance [23, 24]. Thus, understanding what impels cytokine expression toward different patterns contributes to the immune therapy and vaccination scheme [25].

lncRNAs act as pivotal regulators of gene expression in both innate and adaptive immune responses and play a crucial role in important cellular processes, like differentiation and activation of lymphocytes [26, 27]. Distinct lncRNA expression was identified from early $\mathrm{T}$ cells to terminal $\mathrm{T}$ helper (Th) cells, suggesting that lncRNAs could modulate the development and differentiation of $\mathrm{T}$ cells [28]. Consistent with this finding, lncRNA
TMEVPG1 was specifically expressed in Th1 cells and lncR-Ccr2-50AS was proven to regulate Th2 cell differentiation $[29,30]$. The ability of lncRNAs to regulate $\mathrm{CD} 4^{+} \mathrm{T}$ cell differentiation could have crucial implications for $\mathrm{CE}$, with a Th1-predominant immune response in the early infection stage and a Th2-predominant immune response in the late infection stage [31, 32]. Although lncRNAs have a variety of biological functions, the range of potential biological functions of lncRNAs in parasitic infection is vast and still largely unexplored [33, 34]. A recent study found that microRNA (miRNA), lncRNA, and circular RNA (circRNA) had been identified in protoscoleces exosome-like vesicles and hydatid fluid, and was predicted to participate in the parasite-host interactions [35]. Therefore, identifying how lncRNA regulates $\mathrm{CD} 4^{+} \mathrm{T}$ cell differentiation could provide new mechanistic insights and therapeutic targets for CE.

We used microarray analysis to investigate the lncRNA expression profiles in splenic lymphocytes from $\mathrm{rEg}$. P29 immunization of mice with secondary infection of E. granulosus, and it showed a significant decrease in lncRNA028466 by bio-information analysis [36]. We found that after rEg.P29 immunization, the expression of lncRNNA028466 in $\mathrm{CD}^{+} \mathrm{T}$ cells was significantly different from other lncRNAs. We speculated that lncRNA028466 may play an important role in rEg.P29induced immune response. Therefore, lncRNA028466 was selected to further study. However, the function of lncRNA028466 has not been reported. The purpose of our study was to research the influence of lncRNA028466 on the expression of cytokines-producing Th1 and Th2 cells. Furthermore, we will look for the target molecules that interact with IncRNA028466 and further study their interactions. It is hoped that our datasets provide an important resource for future studies of the vaccine of $r E g . P 29$ and the function of lncRNAs in host-parasite interaction.

\section{Methods \\ Mice}

We obtained 6- to 8-week-old female BALB/c mice from the Animal Laboratory Center of Ningxia Medical University (SCXK2018-0004). The mice were raised in pathogen-free conditions, with eight groups of mice in each cage and fed clean food and water. All mouse experiments were permitted by the Ningxia Medical University Institutional Review Committee and carried out in strict accordance with national and institutional guidelines.

\section{rEg.P29 antigen preparation and vaccination protocols}

The recombinant plasmid was preserved in our laboratory. We then converted recombined plasmid P29/ pET28a into E. coli BL21 pLysS and mixed them with LB 
liquid medium for incubation, which induced expression at $37{ }^{\circ} \mathrm{C} 5 \mathrm{~g} / \mathrm{min}$ for $5 \mathrm{~h}$, under the condition of $1 \mathrm{~mol} /$ $\mathrm{mL}$ isopropyl- $\beta$-d-sulfur semi-lactose glycoside (IPTG, Invitrogen). Subsequently, his6-tagged rEg.P29 was purified by nickel chelation affinity (Novagen) following the manufacturer's protocol. Western blot was performed to detect the rEg.P29 purity. Next, we randomly classified 24 mice into two groups of 12 mice as immune and control groups. The immune group was injected subcutaneously with $10 \mu$ g purified $r E g$.P29 protein at three points in the abdomen. The $\mathrm{rEg}$.P29 protein was emulsified twice with phosphate-buffered saltwater (PBS) and Freund's adjuvant in a volume of $100 \mu \mathrm{L}$. Primary immunity used Freund's complete adjuvant, and 2 weeks after the initial immunity, Freund's incomplete adjuvant was used to strengthen immunity. The control group was injected with an equal volume of PBS. Two weeks after the booster immunization, mice were used for later experiments.

\section{Western blot analysis}

The BCA Protein Assay Kit (Beyotime Biotechnology) was used to measure the concentration of proteins. Then, proteins were boiled at $100{ }^{\circ} \mathrm{C}, 10 \mathrm{~min}$, and $12 \%$ sodium dodecyl sulfate-polyacrylamide gel electrophoresis (SDS-PAGE) was used to isolate the protein. PVDF membrane (Solarbio Science \& Technology, Beijing, China) was used to transfer the protein. After $2 \mathrm{~h}$ blockage with $5 \%$ skim milk at room temperature, the primary antibodies were supplemented at $4{ }^{\circ} \mathrm{C}$ for overnight incubation. For $r E g$.P29 protein, the primary antibodies were immune mice and control mice serum (1:500 dilution). For total proteins, the primary antibodies included IFN- $\gamma$ polyclonal antibody (rabbit anti-mouse, 1:500, cat. no. BS3486), IL-2 polyclonal antibody (rabbit anti-mouse, 1:500, cat. no. BS60299), IL-4 polyclonal antibody (rabbit anti-mouse, 1:500, cat. no. BS5764), IL-10 polyclonal antibody (rabbit anti-mouse, 1:1000, cat. no. 20850-1$\mathrm{AP}$ ) and $\beta$-actin monoclonal antibody-HRP (mouse anti-mouse, 1:20,000, cat. no. BS6007MH). The second antibody goat anti-rabbit IgG/HRP $(1: 20,000$, cat. no. ZJ2020-R) was used to incubate the membrane for $2 \mathrm{~h}$ at room temperature. Lastly, 3,3-N-diaminobenzidine tetrahydrochloride horseradish peroxidase color development kit (Solarbio) was used to detect the rEg.P29 protein, and electrochemiluminescence (ECL) (Tiangen, Beijing, China) was used to detect the total proteins.

\section{$\mathrm{CD}^{+} \mathrm{T}, \mathrm{CD}^{+} \mathrm{T}$, and $\mathrm{B}$ cell sorting}

Following booster immunization, mice were treated by cervical dislocation. All spleen and lymphocyte operations were carried out under sterile conditions. Spleens were removed from the two groups. Subsequently, the single-cell suspension was prepared and then the spleen tissue lymphocyte isolation medium kit (Tianjin Hao Yang Biological Manufacture, Tianjin, China) was used to isolate spleen lymphocyte cells following the manufacturer's protocol. Finally, we diluted the cell concentration to $1 \times 10^{7} / \mathrm{mL}$ using a $10 \%$ FBS (Gibco, Grand Island, USA) PBS solution and divided it into three groups in $300 \mu \mathrm{L} /$ tubes. Staining for cell-surface markers was performed, including APC-labeled anti-CD4 (552051), PerCP-Cy5.5-labeled anti-CD3e (562286), PE-labeled anti-CD8 (558106) FITC-labeled anti-CD19 (1575-02S) (BD Biosciences, San Jose, CA, USA), placed at $4{ }^{\circ} \mathrm{C}$ in the dark for $30 \mathrm{~min}$. After washing twice, cells were suspended using $2 \mathrm{~mL}$ PBS with 10\% FBS and sorted by flow cytometry. The purification of $\mathrm{CD}^{+} \mathrm{T}, \mathrm{CD}^{+} \mathrm{T}$, and $\mathrm{B}$ cells was $>99 \%$ (Additional file 1: Fig S1). Finally, collecting $\mathrm{CD}^{+} \mathrm{T}, \mathrm{CD} 8^{+} \mathrm{T}$, and $\mathrm{B}$ cells were collected for use in later experiments.

\section{IncRNA028466 overexpression lentivirus construction and siRNA synthesis}

The endotoxin-free plasmid of lncRNA028466 was extracted using an endotoxin-free plasmid extract kit (Tiangen Biochemical Technology Co., Beijing, China) according to the manual instructions. $293 \mathrm{~T}$ packaging cells (Thermo Fisher Scientific, CN) were cultured with $8 \mathrm{~mL}$ DMEM (Invitrogen) with 10\% FBS (Gibco), 1\% $100 \times$ penicillin-streptomycin solution (Invitrogen) in the condition of $37^{\circ} \mathrm{C}$ and $5 \% \mathrm{CO}_{2}$ before transfection. When the cell density reached $80-90 \%, 293 \mathrm{~T}$ cells were transfected with $9 \mu \mathrm{g}$ pCDH-028466, $9 \mu \mathrm{g}$ pLP1, $9 \mu \mathrm{g}$ $\mathrm{pLP} 2$, and $9 \mu \mathrm{g}$ PLP VSV-G (Invitrogen) in the presence of PolyJet (SignaGen, USA) to package the recombinant lentivirus. After $48 \mathrm{~h}$ of co-incubation, cells and supernatant were collected and added to a $15 \mathrm{~mL}$ tube at $991 \mathrm{~g}$ for $10 \mathrm{~min}$. Then the supernatant that contained the virus was collected and filtered through a $0.45 \mu \mathrm{m}$ filter into a new $15 \mathrm{~mL}$ tube. The supernatant was centrifuged at $50,000 \times g$ at $4{ }^{\circ} \mathrm{C}$ for $2 \mathrm{~h}$. The supernatant was discarded, and the virus particles at the bottom of the tube were resuspended with $100 \mu \mathrm{L}$ DMEM, then divided into PCR tubes and stored at $-80{ }^{\circ} \mathrm{C}$.

Small interfering RNAs (siRNAs) targeted separate sequences of lncRNA028466 were synthesized by Tianjin Sheweisi Biotechnology Company, including siRNA1, siRNA2, and siRNA3. The siRNA1 targeting sequence for lncRNA028466 is 5'-GGU UGA GAU UGG ACG UUU CAU DTD T- $3^{\prime}$ (sense) and $5^{\prime}$-AUG AAA CGU CCA AUC UCA ACC DTD T - $3^{\prime}$ (antisense). The sequence of siRNA2 is $5^{\prime}$-GGU UGA GAU UGG ACG UUU CAU DTD T-3' (sense) and 5'-AAA GAG GGU ACA AGG UUA GGC DTD T- $3^{\prime}$ (antisense). The sequence of siRNA3 is $5^{\prime}$-GGC CAG AUA AGC UGC AAD TDT-3' 
(sense) and 5'-UUG CAG CUC UUA UCU GGC CDT DG $-3^{\prime}$ (antisense).

Naive $\mathrm{CD}^{+} \mathrm{T}$ cell sorting, transfection, and differentiation A healthy female BALB/c mouse spleen was placed on a $70 \mu \mathrm{m}$ nylon cell filter to prepare a single-cell suspension. A magnetic bead isolation kit (Miltenyi Biotec, Bergisch Gladbach, Germany) was used for negatively selecting naive $\mathrm{CD} 4^{+} \mathrm{T}$ cells following the manufacturer's instructions. The purification of naive $\mathrm{CD} 4^{+} \mathrm{T}$ cell populations $\left(\mathrm{CD} 4{ }^{+} \mathrm{CD} 25^{-} \mathrm{CD} 62 \mathrm{~L}^{\text {hi }} \mathrm{CD} 44^{\text {low }}\right)$ was $>90 \%$. Subsequently, naive $\mathrm{CD} 4^{+} \mathrm{T}$ cells were resuspended in RPMI 1640 (Gibco, Grand Island, USA) with $2 \%$ FBS, and were cultivated at $37{ }^{\circ} \mathrm{C}, 5 \% \mathrm{CO}_{2}$ in $1 \times 10^{6}$ cells/well of 48 -well plate, after which $100 \mu \mathrm{L}$ pCDH-CMV and pCDH028466 lentivirus or $20 \mathrm{nM}$ siRNA and negative control siRNA were added in the presence of Lipofectamine 3000 (Thermo Fisher Scientific, CN); total volume was $250 \mu \mathrm{L} /$ well. After $6 \mathrm{~h}$, the transfected cells were removed into a 24-well plate. Then cells were activated with platebound $1 \mu \mathrm{g} / \mathrm{mL}$ anti-CD3 (eBioscience) plus $1 \mu \mathrm{g} / \mathrm{mL}$ anti-CD28, $20 \mathrm{ng} / \mathrm{mL}$ IL-2, $50 \mathrm{ng} / \mathrm{mL}$ IL-12, $10 \mathrm{ng} / \mathrm{mL}$ anti-IL- 4 for Th1 conditions. For generating Th2 cells, we used $1 \mu \mathrm{g} / \mathrm{mL}$ anti-CD28, $20 \mathrm{ng} / \mathrm{mL}$ IL-2, $10 \mathrm{ng} / \mathrm{mL}$ IL-4, $10 \mathrm{ng} / \mathrm{mL}$ anti-IFN- $\gamma$ (BD Bioscience). In the overexpression experiment, micrographs of fluorescent light were captured using a laser scanning confocal microscope. The cells were used for a later experiment after transfection for $96 \mathrm{~h}$.

\section{Quantitative real-time PCR}

Total RNA was extracted from $\mathrm{CD} 4^{+} \mathrm{T}$ cells of the spleen using TRIzol reagent (Invitrogen) according to the manufacturer's procedures. The total RNAs were reverse-transcribed into cDNAs by Revert Aid First Strand cDNA Synthesis Kit (Thermo Fisher Scientific, CN). PCR was accomplished on a StepOnePlus ${ }^{\text {TM }}$ Real-Time PCR instrument according to specifications indicated in the Bestar ${ }^{\mathrm{TM}}$ qPCR MasterMix (SYBR Green) (DBI Bioscience). The PCR was implemented under conditions of pre-denaturation at $95^{\circ} \mathrm{C}$ for $2 \mathrm{~min}$, followed by 40 cycles of denaturation at $95^{\circ} \mathrm{C}$ for $10 \mathrm{~s}$, renaturation at $58{ }^{\circ} \mathrm{C}$ for $34 \mathrm{~s}$, and extension at $72{ }^{\circ} \mathrm{C}$ for $30 \mathrm{~s}$. The gene relative expression was calculated according to the $2^{-\Delta \Delta \mathrm{Ct}}$ method. Specific primer sequences are listed in Table 1.

\section{Flow cytometry analysis}

We cultured the transfected cells under Th1 and Th2 polarizing conditions. Cell Stimulation Cocktail and Protein Transport Inhibitor (Invitrogen) were added into transfected cells in the last $6 \mathrm{~h}$ of incubation. For cell surface staining, we first used $0.1 \%$ BSA, $0.05 \%$ sodium azide PBS buffer to wash the collected cells. Then, the
Table 1 Sequences of primers used for qRT-PCR

\begin{tabular}{ll}
\hline Gene & primer( $\left(5^{\prime} \rightarrow 3^{\prime}\right)$ \\
\hline IncRNA 028466 & F: AGGCCCAGTCTCTCTTGTGA \\
& R: GGGTCTGATGGGTCTCAT \\
IL-2 & F: TGAGCAGGATGGAGAATTACAGG \\
& R: GTCCAAGTTCATCTTCTAGGCAC \\
IFN- $\gamma$ : CTCCCGTGGCTTCTAGTGC & R: GCCTTAGTTGGACAGGATCTG \\
IL-4 & F: ATCATCGGCATTTTGAACGAGG \\
& R: TGCAGCTCCATGAGAACACTA \\
IL-10 & F: GCCACGGCACAGTCATTGA \\
& R: TGCTGATGGCCTGATTGTCTT \\
GAPDH & F: AGGTCGGTGTAACGGATTTG \\
& R: GGGGTCGTGATGGCAACA \\
\hline
\end{tabular}

surface antibody APC-labeled anti-CD4 and PerCP-cy5.5-labeled anti-CD3 (BD Biosciences) were used to stain the cells in the dark for $30 \mathrm{~min}$ at $4{ }^{\circ} \mathrm{C}$. Subsequently, $4 \%$ paraformaldehyde was used to fix the cells under room temperature for $8 \mathrm{~min}$ in the dark, and $0.1 \% \mathrm{BSA}, 0.05 \%$ sodium azide, and $0.1 \%$ saponin (Sigma) PBS buffer was used to permeabilize the cells at room temperature for $2 \mathrm{~h}$ in dark. After washing, PE-labeled anti-IFN- $\gamma$, PElabeled anti-IL-2, PE-labeled anti-IL-4, PE-labeled antiIL-10 (BD Biosciences) were respectively used to stain the cells in the dark for $30 \mathrm{~min}$ at $4{ }^{\circ} \mathrm{C}$. Stained cells were assayed with flow cytometry (BD Biosciences) and the program FlowJo version 10.0 (Tree Star Inc. USA) was used to analyze the data.

\section{ELISA}

Transfected cells were stimulated with Cell Stimulation Cocktail in the last $6 \mathrm{~h}$ of incubation. Supernatants were collected after $96 \mathrm{~h}$ and a specific ELISA kit (BD Biosciences, San Jose, CA, USA) was used to detect the cytokine levels following the manufacturer's protocol.

\section{Statistical analysis}

Using SPSS 17.0 statistical software and GraphPad Prism 6.0 software to analyze the experimental results, the measurement data were represented as mean \pm standard error, according to the comparison between the two groups using the two-tailed $t$-test. The test level was $\alpha=0.05$.

\section{Results}

Microarray analysis revealed significant downregulation of IncRNA028466 transcripts in spleen lymphocytes of mice immunized with rEg.P29 antigen

First, we detected a high purity expression band of $r E g$. P29 antigen at $31 \mathrm{kDa}$ through western blot (Fig. 1a). Microarray analysis revealed that lncRNA028466 was 


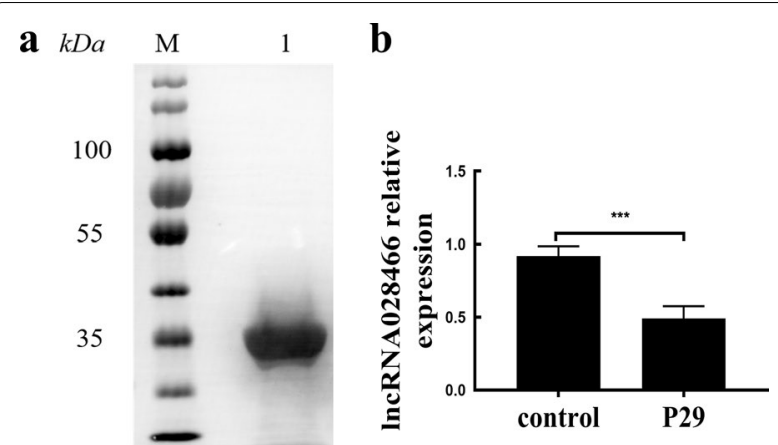

Fig. 1 Microarray analysis reveals significant downregulation of IncRNA028466 transcripts in spleen lymphocytes of mice immunized with rEg.P29 antigen. a rEg.P29 antigen was purified and detected by western blot. $\mathbf{b}$ Validation of IncRNA028466 expression levels in lymphocytes of mice by qRT-PCR. Data were shown as mean \pm SD and represented three separate experiments ( $n=6$ per group). ${ }^{* * *} P<0.001$

downregulated 2.31-fold in spleen lymphocytes of mice immunized with $r E g$.P29 antigen. To verify the expression of lncRNA028466 in spleen lymphocytes following immunization, qRT-PCR was used to determine the downregulation of IncRNA028466. IncRNA028466 exhibited 1.87 -fold-lower expression $(t=7.906$, $P=0.0002)$ compared with that in the control group (Fig. 1b).

The expression of IncRNA028466 was decreased in $\mathrm{CD}^{+} \mathrm{T}$ cells of spleens from mice immunized with rEg.P29 antigen Because lncRNA028466 expression decreased in spleen lymphocytes of mice immunized with rEg.P29 antigen, we aimed to understand the role that IncRNA028466 played in $\mathrm{rEg}$.P29-mediated immune response. We then respectively isolated splenic $\mathrm{CD} 4^{+} \mathrm{T}, \mathrm{CD} 8^{+} \mathrm{T}$, and $\mathrm{B}$ cells from the control and immune groups using flow cytometry. The percentage of $\mathrm{CD} 4^{+} \mathrm{T}, \mathrm{CD} 8^{+} \mathrm{T}$, and $\mathrm{B}$ cells were respectively $21.6 \%, 7.1 \%, 56.7 \%$ in the control group (Fig. 2a) and 26\%, 8.0\%, 56.0\% in the immune group (Fig. 2b). The data indicated that $\mathrm{CD} 4^{+} \mathrm{T}$ cells were increased following immunization with rEg.P29. qRT-PCR was performed to measure the expression of lncRNA028466 in $\mathrm{CD}^{+} \mathrm{T}, \mathrm{CD} 8^{+} \mathrm{T}$, and $\mathrm{B}$ cells. The expression of lncRNA028466 in $\mathrm{CD}^{+} \mathrm{T}$ cells from the
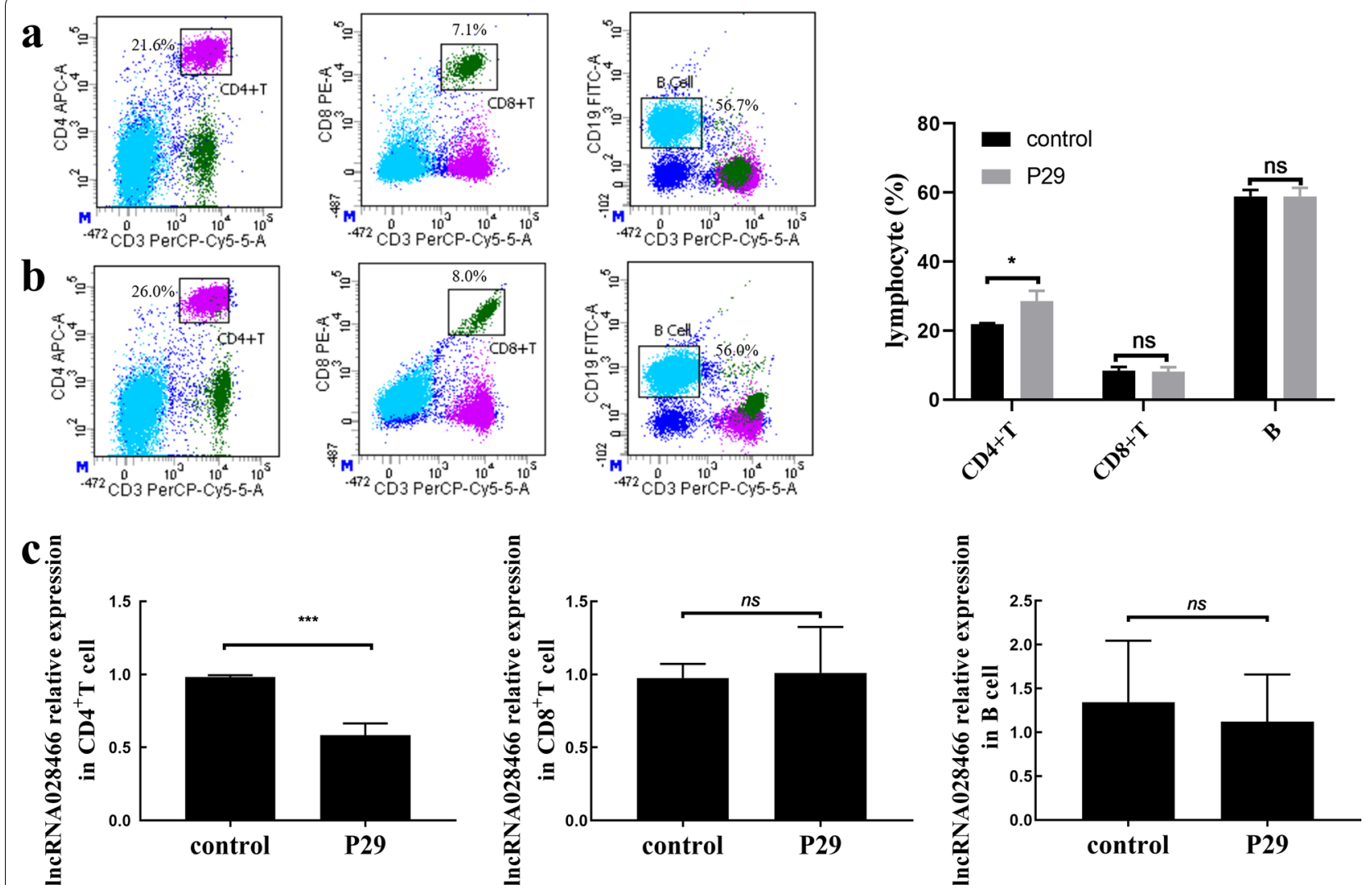

Fig. 2 The expression of IncRNA028466 was decreased in CD4 ${ }^{+} T$ of spleens from mice immunized with rEg.P29 antigen. Following boost immunization, flow cytometry was used to isolate $C D 4^{+} T, C D 8^{+} T$ and $B$ cells. The percentage of $C D 4^{+} T, C D 8^{+} T$ and $B$ cells in the control (a) and immune groups (b) are shown. c The expression of IncRNA028466 in CD4 ${ }^{+} T, C D 8^{+} T$ and $B$ cells was measured by qRT-PCR. Results are shown as mean $\pm S D$ and represent three separate experiments ( $n=6$ per group). ${ }^{*} P<0.05,{ }^{* *} P<0.01$, ns: not significant 
immune group was 1.68 times lower $(t=9.651, P<0.001)$ than the control group; however, there were no prominent changes in $\mathrm{CD} 8^{+} \mathrm{T}$ and B cells (Fig. 2c). All in all, these data suggested that lncRNA028466 could affect cellular immune responses associated with $\mathrm{rEg}$.P29 antigen immunity.

\section{Overexpression of IncRNA028466 biased naive $\mathrm{CD}^{+} \mathrm{T}$ cell differentiation toward the Th2 phenotype}

To understand the role that IncRNA028466 played in $\mathrm{CD} 4^{+} \mathrm{T}$ cell differentiation, we isolated splenic naive $\mathrm{CD}^{+} \mathrm{T}$ lymphocytes. In addition, we used $293 \mathrm{~T}$ cells packing lncRNA028466 overexpression lentivirus (pCDH-028466, green fluorescent protein [GFP]) and empty vector ( $\mathrm{pCDH}-\mathrm{CMV}, \mathrm{GFP}$ ). The expression of GFP was detected by a laser scanning confocal microscope (Olympus) (Fig. 3a). Then, the transfection efficiency of transfection naive $\mathrm{CD}^{+} \mathrm{T}$ cells with $\mathrm{pCDH}-028466$ and $\mathrm{pCDH}-\mathrm{CMV}$ was detected by qRT-PCR analysis. lncRNA028466 overexpression lentivirus exhibited a 28.56-fold-higher expression $(t=7.924, P=0.0005)$ compared with empty vector (Fig. 3a). The result suggested that the lncRNA028466 overexpression lentiviral vector was successfully transfected into the cells. Subsequently, naive $\mathrm{CD} 4^{+} \mathrm{T}$ cells were infected with $\mathrm{pCDH}-\mathrm{CMV}$ and pCDH-028466. Then, the expression of Th1-related cytokines IL-2, IFN- $\gamma$, and Th2-related cytokines IL-10, IL-4 were detected respectively from mRNA, protein, and extracellular levels by qRT-PCR, western blot and ELISA. As a result, according to qRT-PCR analysis, overexpression of lncRNA028466 inhibited the expression of IFN- $\gamma(t=7.564, P=0.0003)$ and IL-2 $(t=13.28$, $P<0.001)$ and increased the expression of IL-4 $(t=4.157$, $P=0.006)$ and IL-10 ( $t=7.367, P=0.0003)$ (Fig. 3b). The result was confirmed by western blot and ELISA analysis (Fig. 3c, d).

Considering the result that overexpression of lncRNA028466 upregulated Th2-related cytokines IL-4 and IL-10 expression, and downregulated Th1-related cytokines IFN- $\gamma$ and IL-2 expression, we studied the role of lncRNA028466 in $\mathrm{CD}^{+} \mathrm{T}$ cell differentiation. pCDH-CMV and pCDH-028466 were transfected into naive $\mathrm{CD} 4^{+} \mathrm{T}$ cells, which were cultured in the Th1 and Th2 cell-polarizing conditions. The FACS analysis showed that lncRNA028466 overexpression of lentivirus-transfected cells increased differentiation toward IL-4- and IL-10- (Fig. 3e) producing Th2 subtype, compared with the empty vector group. However, there was a remarkable reduction in IFN- $\gamma$ - and IL-2-producing (Fig. 3e) Th1 cells. All in all, these results may indicate that overexpression of IncRNA028466 biases naive $\mathrm{CD} 4^{+} \mathrm{T}$ cell differentiation toward the Th2 phenotype.

\section{Knockdown of IncRNA028466 promotes naive CD4 ${ }^{+}$T cell differentiation toward the Th1 subgroup}

To confirm whether lncRNA028466 contributes to $\mathrm{CD} 4^{+} \mathrm{T}$ cell differentiation, we designed siRNA to knock down its expression in naive $\mathrm{CD} 4^{+} \mathrm{T}$ cells. For siRNA interference efficiency, siRNA1, siRNA2, and siRNA3 were respectively transfected into naive $\mathrm{CD} 4^{+} \mathrm{T}$ cells, and qRT-PCR was performed. According to the result (Fig. 4a), siRNA1 efficiently knocked down lncRNA028466 by 5.88 -fold $(t=17.98, P<0.001)$ compared with negative siRNA and was used for later experiments. Subsequently, siRNA1 and negative siRNA were transfected into naive $\mathrm{CD} 4^{+} \mathrm{T}$ cells, and qRT-PCR, western blot, and ELISA were performed to measure the expression of Th1-related cytokines IL-2, IFN- $\gamma$, and Th2-related cytokines IL-10, IL-4. We found that knockdown of IncRNA028466 upregulated IL-2 $(t=14.10, P<0.0001)$ production and downregulated IL-10 $(t=6.822, P=0.0005)$ production (Fig. $4 \mathrm{~b}-\mathrm{d})$. There was a mild increase in IFN- $\gamma$, and a mild decrease in IL-4 (Fig. 4b-d); however, the levels of IFN- $\gamma$ and IL-4 did not reach statistical significance. The low levels may have gone undetected.

Similarly, siRNA-transfected naive $\mathrm{CD} 4^{+} \mathrm{T}$ cells were placed in the Th1 and Th2 cell-polarizing conditions. The FACS analysis showed that siRNA-transfected cells differentiated toward IFN- $\gamma$ - and IL-2-producing Th1 subtype (Fig. 4e), compared with a negative control group. However, there was a remarkable reduction in the Th2-related cytokines IL-4 and IL-10 (Fig. 4e). Taken together, the results indicate that knockdown of lncRNA028466 promotes naive $\mathrm{CD} 4^{+} \mathrm{T}$ cell differentiation toward Th1 cells.

\footnotetext{
(See figure on next page.)

Fig. 3 Overexpression of IncRNA028466 biases naive $C D 4^{+} T$ cell differentiation toward the Th2 phenotype. a Validation of the transfection efficiency of IncRNA028466 overexpression lentivirus by qRT-PCR and representative image of the expression of GFP ( $\times 40)$ was detected by a laser scanning confocal microscope (Olympus). b The mRNA expression of IFN- - , IL-2, IL-4, and IL-10 was measured by qRT-PCR. c The protein levels of cytokines were determined by western blot. $\mathbf{d}$ The supernatants were detected by ELISA. $\mathbf{e}$ The differentiation of the transfected naive CD4 ${ }^{+} T$ cells was measured by FACS. The scattered dots in the box represent the expression of IFN- $\gamma$ and IL-2 producing Th1 cells, and IL-4 and IL-10 producing Th2 cells. Results are shown as mean \pm SD and represent three separate experiments ( $n=6$ per group). Vector represents empty vector, pCDH-028466 represents IncRNA028466 overexpression vector. ${ }^{*} P<0.05,{ }^{* *} P<0.01,{ }^{* * *} P<0.001$
} 


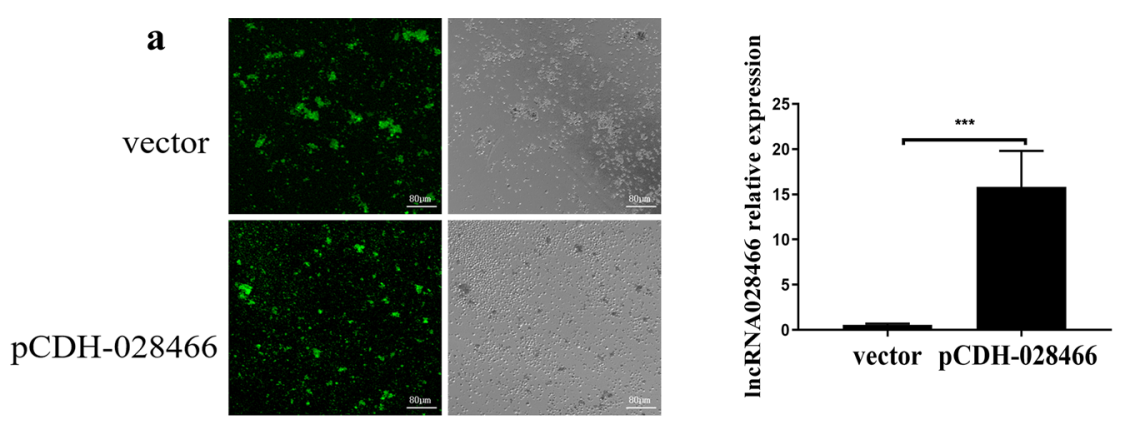

b

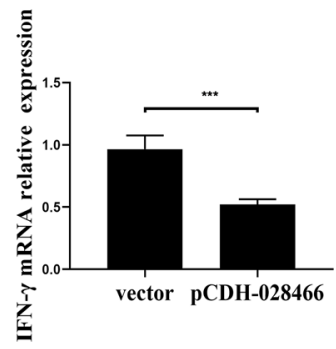

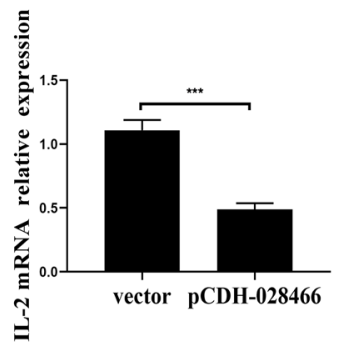
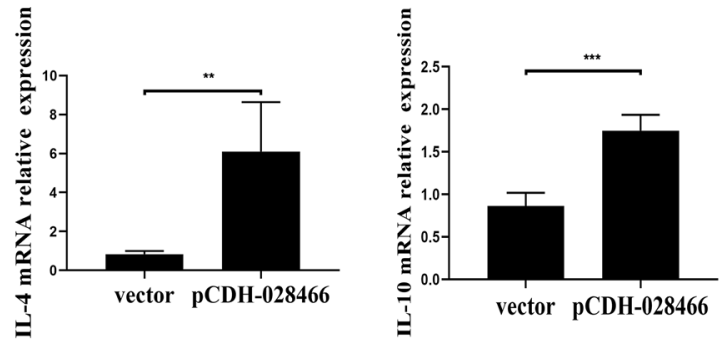

c IFN- $\gamma$
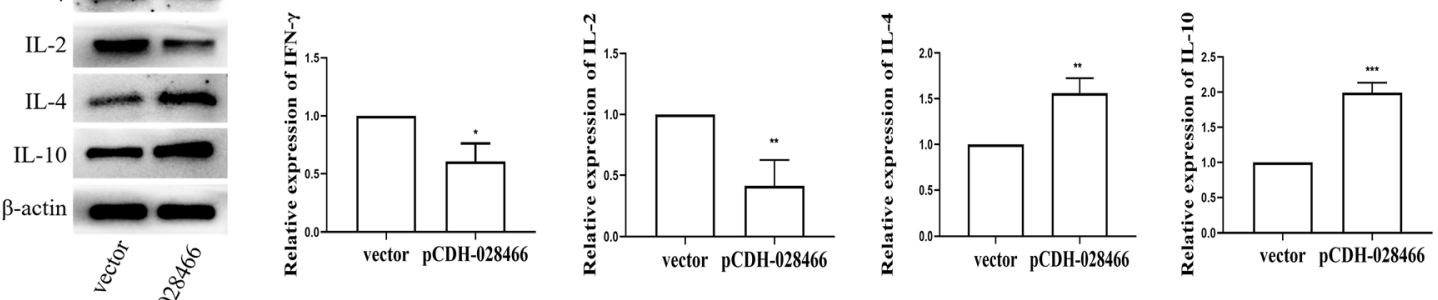

d

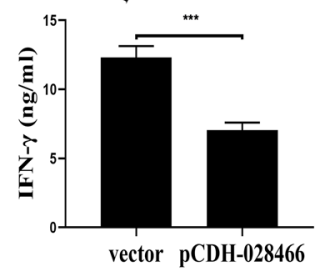

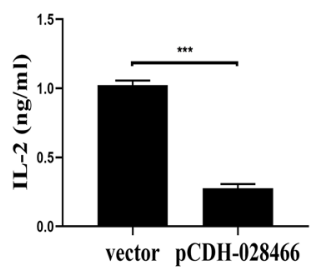
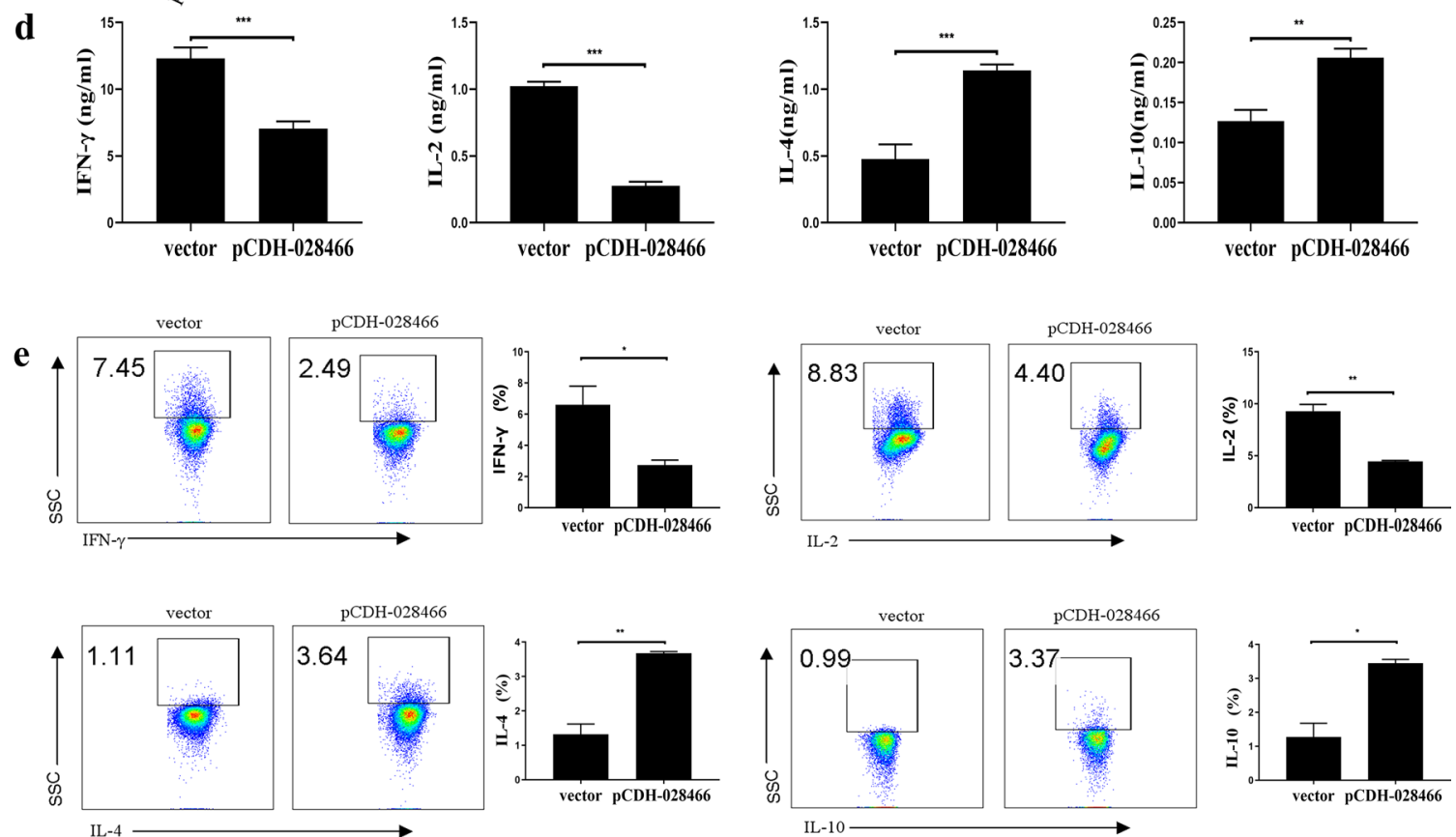


\section{Discussion}

The purpose of our study was to research the contribution of lncRNA028466 to the differentiation of splenic $\mathrm{CD}^{+} \mathrm{T}$ cells. $\mathrm{CD}^{+} \mathrm{T}$ cells are major participants in $\mathrm{CE}$, and the bias of $\mathrm{CD} 4^{+} \mathrm{T}$ cells toward the Th2 subset causes an unbalanced secretion of cytokines producing Th subsets, which results in the chronic progression of CE $[37,38]$. Consistent with this theory, in our study, the proportion of $\mathrm{CD}^{+}{ }^{+} \mathrm{T}$ cells was augmented following immunization with $\mathrm{rEg}$.P29. This meant that $\mathrm{CD} 4^{+} \mathrm{T}$ cells participate in the immunoreaction associated with $\mathrm{rEg}$. P29.

The expression of lncRNA was lineage-specific and played a crucial role during $\mathrm{CD} 4^{+} \mathrm{T}$ cell differentiation toward Th1 and Th2 cells [28, 39, 40]. At present, the relevance of lncRNA to the pathogenesis, host resistance, and parasite evasion during parasitic infection is emphasized [34]. There is increasing attention to the contribution of lncRNA to E. granulosus infection [35]. This kind of research will contribute to the reasonable design of immune therapy and vaccination schemes. In the present study, we discovered that IncRNA028466 significantly decreased in $\mathrm{CD} 4^{+} \mathrm{T}$ cells with the rEg.P29 immunized group. On the one hand, overexpression of lncRNA028466 not only enhanced differentiation of Th2 cells but also promoted the secretion of Th2-related cytokines IL-10 and IL-4, but suppressed the expression of Th1-related cytokines IFN- $\gamma$ and IL-2. On the other side, the knockdown of lncRNA028466 inhibited the differentiation of Th2 cells and promoted the differentiation of Th1 cells. Based on this finding, we propose that lncRNA028466 may participate in the protective $\mathrm{r} E g$.
P29-mediated immunity by modulating Th1 and Th2 cytokine expression.

The polarization of the Th1 and Th2 subset is a crucial determinant of whether the response to the pathogen will confer protection to the host or exacerbate the disease [24]. IFN- $\gamma$ is demonstrated to inhibit Echinococcus activity and contributes to the formation of the protective immunity mediated by Th1 cells during E. granulosus infection [25, 38]. Mouse experimental studies supporting IL-4- and IL-10-mediated immunosuppression may be key to parasite evasion and survival $[19,41]$. This study demonstrated that the increased Th1 immune response was related to lower IL-4 and IL-10 expression, as well as lncRNA028466 overexpression. The immunoprotection of $\mathrm{rEg}$.P29 may be realized by lncRNA028466 regulating the expression of cytokines associated with Th1 and Th2 cells. However, our study just preliminary investigated the role of lncRNA028466 in regulating the expression of Th1- and Th2-associated cytokines in vitro. To further demonstrate the result, we will further study the function of lncRNA028466 in vivo and in vitro.

\section{Conclusions}

In conclusion, lncRNA028466 may be involved in $\mathrm{r} E g$. P29 vaccination-mediated Th1 protective immunity. The study of the function of lncRNA in $\mathrm{T}$ helper responses is an area that needs to be explored, which will help deepen our learning about the complicated immune response. We expect that further characterization of the identified lncRNA028466 will reveal the important role of lncRNA in host-parasite interaction and $\mathrm{CD} 4^{+} \mathrm{T}$ cell differentiation.

\footnotetext{
(See figure on next page.)

Fig. 4 Downregulation of IncRNA028466 promotes naive CD4 ${ }^{+} T$ cell differentiation toward the Th1 phenotype. a The interference efficiency of siRNAs was tested by qRT-PCR. $\mathbf{b}$ The mRNA expression of cytokines in the transfected naive CD4 ${ }^{+} T$ cells was tested by qRT-PCR. $\mathbf{c}$ The protein levels of cytokines were determined by western blot. $\mathbf{d}$ The supernatants were detected by ELISA. $\mathbf{e}$ The differentiation of the transfected naive $\mathrm{CD}^{+}{ }^{+} \mathrm{T}$ cells was measured by FACS. The scattered dots in the box represent the expression of IFN- $\gamma$ and IL-2 producing Th1 cells, and IL-4, and IL-10 producing Th2 cells. The data came from a single experiment and represented three separate experiments. Negative represented the control group, siRNA1 represented the IncRNA028466 knockdown group. Data were expressed as mean \pm SD and represented three separate experiments $(n=6$ per group). ${ }^{*} P<0.05,{ }^{* *} P<0.01,{ }^{* *} P<0.001$, ns: not significant
} 
a

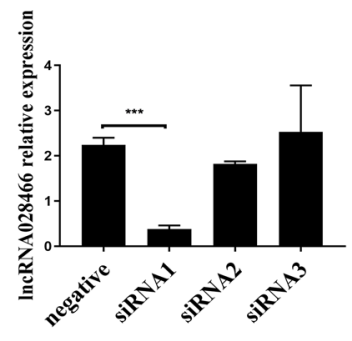

b
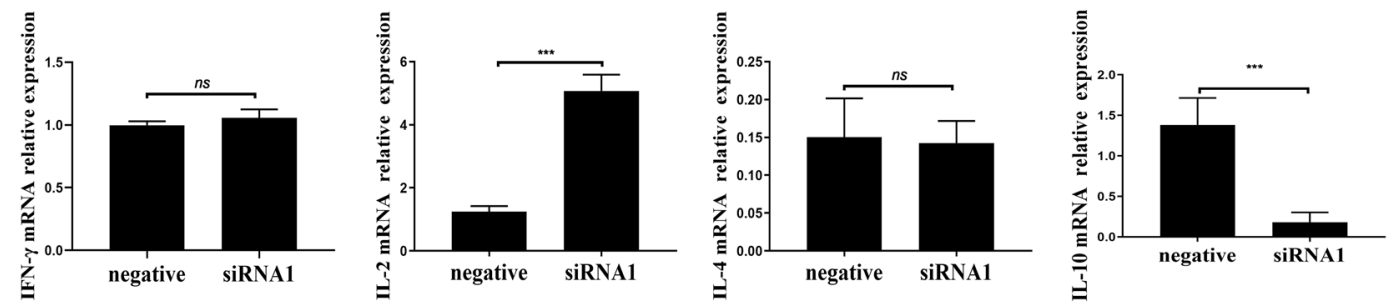

c
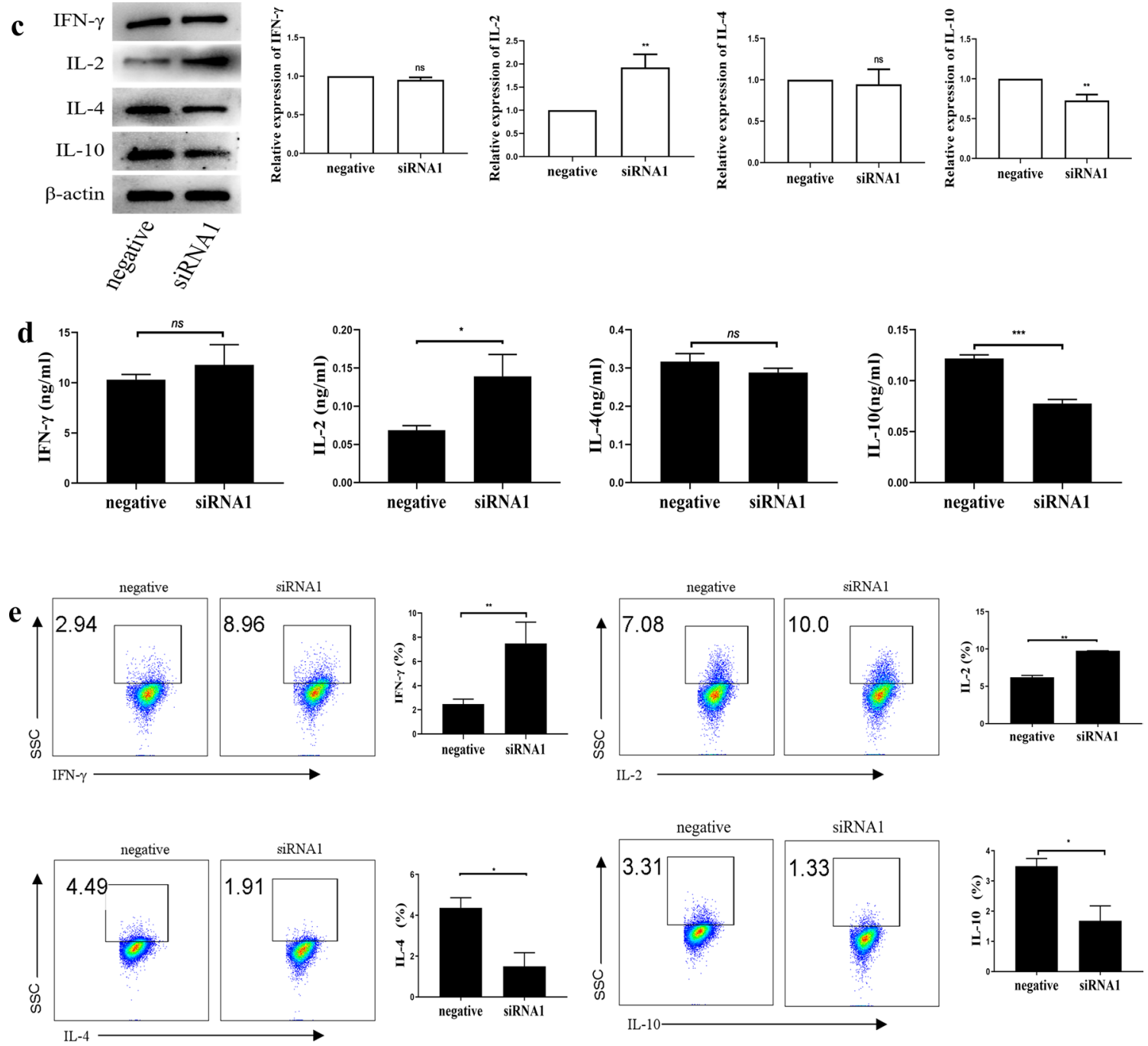


\begin{abstract}
Abbreviations
Eg: Echinococcus granulosus; IncRNA: Long noncoding RNA; rEg.P29:

Recombinant Echinococcus granulosus antigen P29; PBS: Phosphate-buffered solution; IPTG: Isopropyl $\beta$-D-thiogalactoside; FBS: Fetal bovine serum; DMEM: Dulbecco's modified Eagle's medium; RPMI1640: Roswell Park Memorial Institute; qRT-PCR: Quantitative real-time polymerase chain reaction; Treg: Natural regulatory cell; BSA: Bovine serum albumin.
\end{abstract}

\section{Supplementary Information}

The online version contains supplementary material available at https://doi. org/10.1186/s13071-021-04795-2.

Additional file 1: Figure S1. The purification of $\mathrm{CD}^{+}{ }^{+}, \mathrm{CD} 8^{+} \mathrm{T}$, and $\mathrm{B}$ cells. CD4 ${ }^{+} \mathrm{T}, \mathrm{CD} 8^{+} \mathrm{T}$, and $\mathrm{B}$ cells from spleen of mice immunized with $\mathrm{rEg}$. P29 antigen were sorted by flow cytometry. a The purification of CD4 ${ }^{+} \mathrm{T}$ cells. $\mathbf{b}$ The purification of $\mathrm{CD}^{+} \mathrm{T}$ cells. $\mathbf{c}$ The purification of $\mathrm{B}$ cells.

\section{Acknowledgements}

We thank Ningxia Medical University Science and Technology Center for the experimental environment.

\section{Authors' contributions}

WZ was in charge of the project design; CW and SHY were responsible for conducting the experiments, the data analysis, and paper writing; XCD and JT were responsible for designing and synthesizing relevant primers in the experiment; JHY was responsible for flow cytometry sorting of lymphocyte subsets; YNW was in charge of the revision; MXZ and NN were responsible for the experimental guidance. All authors read and approved the final manuscript.

\section{Funding}

Supported by the Key Research and Development Project of Ningxia Hui Autonomous Region [No. 2018BEG02003].

\section{Availability of data and materials}

The datasets supporting the findings of this article are included within the paper. The study-related data can be obtained from the corresponding author upon request.

\section{Declarations}

Ethics approval and consent to participate

All mouse experiments were given permission by the Ningxia Medical University Institutional Review Committee (Permit number: SCXK2018-0004) and carried out in strict accordance with national and institutional guidelines. The data obtained met the appropriate ethical requirements.

\section{Consent for publication}

Not applicable.

\section{Competing interests}

The authors declare that they have no competing interests.

\section{Author details}

${ }^{1}$ Department of Medical genetics and Cell biology, School of Basic Medical Science of Ningxia Medical University, Yinchuan 750004, Ningxia Hui Autonomous Region, People's Republic of China. ${ }^{2}$ Center of Scientific Technology of Ningxia Medical University, Yinchuan 750004, Ningxia Hui Autonomous Region, People's Republic of China. ${ }^{3}$ Ningxia Key Laboratory of Prevention and Control of Common Infectious Diseases of Ningxia Medical University, Yinchuan 750004, Ningxia Hui Autonomous Region, People's Republic of China.

Received: 18 February 2021 Accepted: 20 May 2021

Published online: 03 June 2021

\section{References}

1. Anvari D, Rezaei F, Ashouri A, Rezaei S, Majidiani H, Pagheh AS, et al. Current situation and future prospects of Echinococcus granulosus vaccine candidates: a systematic review. Transbound Emerg Dis. 2020;6:1.

2. Li Z, Zhang C, Li L, Bi X, Li L, Yang S, et al. The local immune response during Echinococcus granulosus growth in a quantitative hepatic experimental model. Sci Rep. 2019;9:19612.

3. Moro P, Schantz PM. Echinococcosis: a review. Int J Infect Dis. 2009;13:125-33.

4. Wen H, Vuitton L, Tuxun T, Li J, Vuitton DA, Zhang W, et al. Echinococcosis: Advances in the 21st century. Clin Microbiol Rev. 2019;32:e18-75.

5. Khanna A, Kumar J, Vargas MA, Barrett L, Katewa S, Li P, et al. A genomewide screen of bacterial mutants that enhance dauer formation in $C$. elegans. Sci Rep. 2016;6:38764.

6. Wang L, Gao J, Lan X, Zhao H, Shang X, Tian F, et al. Identification of combined T-cell and B-cell reactive Echinococcus granulosus 95 antigens for the potential development of a multi-epitope vaccine. Ann Transl Med. 2019;7:652.

7. Larrieu E, Gavidia CM, Lightowlers MW. Control of cystic echinococcosis: Background and prospects. Zoonoses Public Health. 2019;66:889-99.

8. Heath DD, Holcman B. Vaccination against echinococcus in perspective. Acta Trop. 1997;67:37-41.

9. Zhang Q, Ye J, Zheng H. Dexamethasone attenuates echinococcosisinduced allergic reactions via regulatory T cells in mice. BMC Immunol. 2016;17:4.

10. Larrieu E, Herrero E, Mujica G, Labanchi JL, Araya D, Grizmado C, et al. Pilot field trial of the Eg95 vaccine against ovine cystic echinococcosis in Rio Negro, Argentina: Early impact and preliminary data. Acta Trop. 2013;127:143-51.

11. González G, Spinelli P, Lorenzo C, Hellman U, Nieto A, Willis A, et al. Molecular characterization of P-29, a metacestode-specific component of Echinococcus granulosus which is immunologically related to, but distinct from, antigen 5. Mol Biochem Parasitol. 2000;105:177-85.

12. Boubaker G, Gottstein B, Hemphill A, Babba H, Spiliotis M. Echinococcus P29 antigen: molecular characterization and implication on post-surgery follow-up of CE patients infected with different species of the Echinococcus granulosus complex. PLOS ONE. 2014;9:e98357.

13. Shi Z, Wang Y, Li Z, Li Z, Bo Y, Ma R, et al. Cloning, expression, and protective immunity in mice of a gene encoding the diagnostic antigen P-29 of Echinococcus granulosus. Acta Biochim Biophys Sin. 2009;41:79-85.

14. Wang H, Li Z, Gao F, Zhao J, Zhu M, He X, et al. Immunoprotection of recombinant Eg.P29 against Echinococcus granulosus in sheep. Vet Res Commun. 2016;40:73-9.

15. Siracusano A, Delunardo F, Teggi A, Ortona E. Cystic echinococcosis: aspects of immune response, immunopathogenesis and immune evasion from the human host. Endocr Metab Immune Disord Drug Targets. 2012;12:16-23.

16. Tubo NJ, Jenkins MK. CD4 ${ }^{+} \mathrm{T}$ Cells: guardians of the phagosome. Clin Microbiol Rev. 2014;27:200-13.

17. Rogan MT. T-cell activity associated with secondary infections and implanted cysts of Echinococcus granulosus in BALB/c mice. Parasite Immunol. 1998;20:527-33.

18. Pang N, Zhang F, Li S, Zhu Y, Zhang C, An M, et al. TGF- $\beta /$ Smad signaling pathway positively up-regulates the differentiation of interleukin9-producing $\mathrm{CD} 4{ }^{+} \mathrm{T}$ cells in human Echinococcus granulosus infection. J Infection. 2018;76:406-16.

19. Amri M, Mezioug D, Touil-Boukoffa C. Involvement of IL-10 and IL-4 in evasion strategies of Echinococcus granulosus to host immune response. Eur Cytokine Netw. 2009;20:63.

20. Dorosti Z, Tolouei S, Khanahmad H, Jafari R, Jafaee F, Sharafi SM, et al. IL-4 gene expression in adventitial layer (fibrous layer) of hepatic ovine and bovine hydatid cysts. J Parasit Dis. 2016;40:855-9.

21. Siracusano A, Delunardo F, Teggi A, Ortona E. Host-parasite relationship in cystic echinococcosis: an evolving story. Clin Dev Immunol. 2012;2012:639362.

22. Gabaglia CR, Valle MT, Fenoglio D, Barcinski MA, Manca F. CD4(+) T cell response to Leishmania spp. in non-infected individuals. Hum Immunol. 2000;61:531-7.

23. Maizels RM, Bundy DA, Selkirk ME, Smith DF, Anderson RM. Immunological modulation and evasion by helminth parasites in human populations. Nature. 1993;365:797-805. 
24. Jankovic D, Liu Z, Gause WC. Th1- and Th2-cell commitment during infectious disease: asymmetry in divergent pathways. Trends Immunol. 2001:22:450-7.

25. Corrêa F, Hidalgo C, Stoore C, Jiménez M, Hernández M, Paredes R. Cattle co-infection of Echinococcus granulosus and Fasciola hepatica results in a different systemic cytokine profile than single parasite infection. PLoS ONE. 2020;15:e238909.

26. Chen YG, Satpathy AT, Chang HY. Gene regulation in the immune system by long noncoding RNAs. Nat Immunol. 2017;18:962-72.

27. Pagani M, Rossetti G, Panzeri I, Candia P, Bonnal RJ, Rossi RL, et al. Role of microRNAs and long-non-coding RNAs in CD4(+) T-cell differentiation. Immunol Rev. 2013;253:82-96.

28. Hu G, Tang Q, Sharma S, Yu F, Escobar TM, Muljo SA, et al. Expression and regulation of intergenic long noncoding RNAs during $T$ cell development and differentiation. Nat Immunol. 2013;14:1190-8.

29. Vigneau S, Rohrlich PS, Brahic M, Bureau JF. Tmevpg1, a candidate gene for the control of Theiler's virus persistence, could be implicated in the regulation of gamma interferon. J Virol. 2003;77:5632-8.

30. Heward JA, Lindsay MA. Long non-coding RNAs in the regulation of the immune response. Trends Immunol. 2014:35:408-19.

31. Rostami-Rad S, Jafari R, Yousofi DH. Th1/Th2-type cytokine profile in C57 black mice inoculated with live Echinococcus granulosus protoscolices. J Infect Public Health. 2018;11:834-9.

32. Rigano R, Profumo E, Buttari B, Teggi A, Siracusano A. Cytokine gene expression in peripheral blood mononuclear cells (PBMC) from patients with pharmacologically treated cystic echinococcosis. Clin Exp Immunol. 1999;118:95-101.

33. Yu A, Wang Y, Yin J, Zhang J, Cao S, Cao J, et al. Microarray analysis of long non-coding RNA expression profiles in monocytic myeloid-derived suppressor cells in Echinococcus granulosus-infected mice. Parasit Vectors. 2018:11:327.
34. Menard KL, Haskins BE, Denkers EY. Impact of Toxoplasma gondii infection on host non-coding RNA responses. Front Cell Infect Microbiol. 2019;9:132.

35. Zhang X, Gong W, Cao S, Yin J, Zhang J, Cao J, et al. Comprehensive analysis of non-coding RNA profiles of exosome-like vesicles from the protoscoleces and hydatid cyst fluid of Echinococcus granulosus. Front Cell Infect Microbiol. 2020;10:316

36. Xue QT. Screening of differentially expressed long non-coding RNA by the recombinant antigen $\mathrm{P} 29$ induced immune protection after Echinococcus granulosus infected host. Ningxia Medical University. 2017.

37. Baz A, Carol H, Fernández V, Mourglia-Ettlin G, Nieto A, Örn A, et al. Echinococcus granulosus: Induction of T-independent antibody response against protoscolex glycoconjugates in early experimental infection. Exp Parasitol. 2008;119:460-6.

38. Rahimi HR, Sarkari B, Mohammadzadeh T, Sadjjadi SM. Immune responses to antigens of in vitro reared Echinococcus granulosus adult worms in Balb/c mice. Iran J Immunol. 2011;8:236.

39. West KA, Lagos D. Long non-coding RNA function in CD4(+) T cells: what we know and what next? Noncoding RNA. 2019;5:43.

40. Zhang F, Liu G, Wei C, Gao C, Hao J. Linc-MAF-4 regulates Th1/Th 2 differentiation and is associated with the pathogenesis of multiple sclerosis by targeting MAF. FASEB J. 2016;31:519-25.

41. Schopf LR, Hoffmann KF, Cheever AW, Urban JJ, Wynn TA. IL-10 is critical for host resistance and survival during gastrointestinal helminth infection. J Immunol. 2002:168:2383-92.

\section{Publisher's Note}

Springer Nature remains neutral with regard to jurisdictional claims in published maps and institutional affiliations.
Ready to submit your research? Choose BMC and benefit from:

- fast, convenient online submission

- thorough peer review by experienced researchers in your field

- rapid publication on acceptance

- support for research data, including large and complex data types

- gold Open Access which fosters wider collaboration and increased citations

- maximum visibility for your research: over $100 \mathrm{M}$ website views per year

At BMC, research is always in progress.

Learn more biomedcentral.com/submissions 